\title{
Peripheral vowels in Tashlhiyt Berber are phonologically long: evidence from Tagnawt, a secret language used by women \\ Mohamed Lahrouchi ${ }^{1} \&$ Philippe Ségéral ${ }^{2}$ \\ ${ }^{1}$ CNRS \& Université Paris $8 /{ }^{2}$ Université Paris 7
}

Abstract: An outstanding issue in Tashlhiyt Berber phonology is the status of the short central vowel (schwa) that appears in certain consonant clusters, and its relation to the remaining (peripheral) vowels in the language. We show that within Tagnawt, a secret language in Tashlhiyt Berber used by women, peripheral vowels are underlyingly long, in that they connect to two skeletal positions. They become unassociated when they have access to only one position. Then, depending on phonotactic conditions, this skeletal position remains empty or surfaces as schwa. In particular, it is demonstrated that Tagnawt formations are all built upon a fixed-shape template fundamentally designed to accommodate three rootconsonants. Accordingly, when the Tashlhiyt input is quadriconsonantal, one root-consonant is regularly discarded. In certain cases, however, all four consonants are maintained, except that a schwa systematically appears in one of the vocalic positions where the vowel $a$ normally surfaces. This cannot be accounted for unless the proposal on the representation of peripheral vowels and schwa is assumed.

Keywords: morphophonology, template, vowel length, secret languages, Tashlhiyt Berber, Tagnawt.

The vowel system of Tashlhiyt Berber presents three peripheral vowels [i], [a] and [u] and one central vowel, a schwa [ə]. The status of the latter, which appears in certain consonant clusters, is still controversial. Two conflicting hypotheses exist: one claims that these schwas are mere transitional vocoids that have no syllabic role (Dell and Elmedlaoui 2002), the other 
suggests that they are actually epenthetic, filling syllable nuclei that would otherwise be empty (Coleman 1996, 1999, 2001).

Following the proposal put forth in Lowenstamm (1991) and taken up in Bendjaballah (2001, 190, and 2005) and Idrissi (2000, 103), we claim that in Tashlhiyt Berber peripheral vowels are underlyingly associated to two V-positions (1a). ${ }^{1}$ They are unassociated when only one V-position is available. Then, depending on phonotactic conditions, the V-position remains silent or surfaces as [ə] (1b):

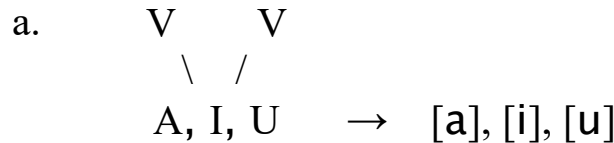

b. $\quad \mathrm{V}$
A, I, U
[a], [i], [u]
$\mathrm{A}, \mathrm{I}, \mathrm{U} \quad \rightarrow \quad[\partial] / \varnothing$

The purpose of the present note is to show that facts in Tagnawt ${ }^{2}$, a secret language in Tashlhiyt, used by women in the South-West of Morocco, clearly militate for the assumptions in (1).

Before we present in section 2 our argument on the phonological representation of the peripheral vowels and the central vowel in Tashlhiyt Berber, it is necessary to survey the morphology of Tagnawt. In section 1, the focus will be on templatic activity underlying word formation in this language.

\section{The template in Tagnawt}

Let us begin with triconsonantal formations ${ }^{3}$. Examples are given in (2):

\footnotetext{
${ }^{1}$ The proposal in (1) is a condition on the association of I, A and U to V-positions. It does not affect the phonetic level. The three vowels surface as short in Tashlhiyt Berber.

2 Tagnawt is the feminine form of the adjective agnaw "dumb".

${ }^{3}$ All data in Tagnawt are taken from Douchaïna (1996 and 1998). Some minor phonological processes such as the transfer of labiovelarization in Tagnawt and consonant assimilations are ignored, as they do not affect the analysis proposed here. Furthermore, some Tagnawt forms are given by Douchaïna (1996 and 1998) with a gemination of $\mathrm{R}_{2}$ paralleling the one that Tashlhiyt input displays: e. g. ajnnaqqbwaqqb $<\mathrm{nqqb}$ make a hole in. Though these formations are possibly significant, we have not retained them, since Douchaïna's notation is not consistent: in several forms, indeed, the gemination of $\mathrm{R}_{2}$ in Tahshliyt forms is not kept in related Tagnawt
} 
(2)

\begin{tabular}{|c|c|c|}
\hline Tashlhiyt & Tagnawt & \\
\hline skr & ajssakrwakr & do \\
\hline i-ksud & ajkkasd'wasd & he is afraid \\
\hline$n-s^{5} b r$ & ajss`abrwabr & we wait, endure \\
\hline wwarg & ajwwargwarg & dream \\
\hline md'uru & $\operatorname{ajmmad}^{\top} \mathrm{rwad}^{\top} \mathrm{r}$ & feel better \\
\hline sawl & ajssawlwawl & speak \\
\hline $\mathrm{l}-\hbar \mathrm{ml}$ & 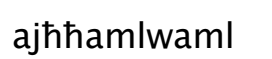 & load \\
\hline$t-$ afrux-t & ajffarxwarx & girl \\
\hline t-aknari-t & ajkkanrwanr & prickly pear \\
\hline
\end{tabular}

First, we note that any affixal (in the examples in (2): the $i-3 m s$ and $n-1 p$ verbal markers, the $\mathrm{t}-\ldots-\mathrm{t}$ feminine nominal marker and the $\mathrm{I}-$ definite article from Moroccan Arabic) or vocalic material of the input (i.e. the Tashlhiyt form) is discarded: only the three root-consonants (henceforth $\mathrm{R}_{1}, \mathrm{R}_{2}, \mathrm{R}_{3}$ ) are kept in Tagnawt.

Then, the following operations are observed:

i. aj- is prefixed and -wa- inserted immediately to the right of $\mathrm{R}_{3}$;

ii. $\mathrm{R}_{1}$ is geminated;

iii. $R_{2}$ and $R_{3}$ are reduplicated to the right of the infixed -wa-;

iv. the form is uniformly vocalized in a.

All Tagnawt triconsonantal formations are thus of the form:

$$
\begin{array}{llllllllllll}
\text { a } & j & R_{1} & R_{1} & \text { a } & R_{2} & R_{3} & \text { w } & \text { a } & R_{2} & R_{3}
\end{array}
$$


Our claim is that this uniform shape stems from a unique template of the form in (3): ${ }^{4}$

(3)

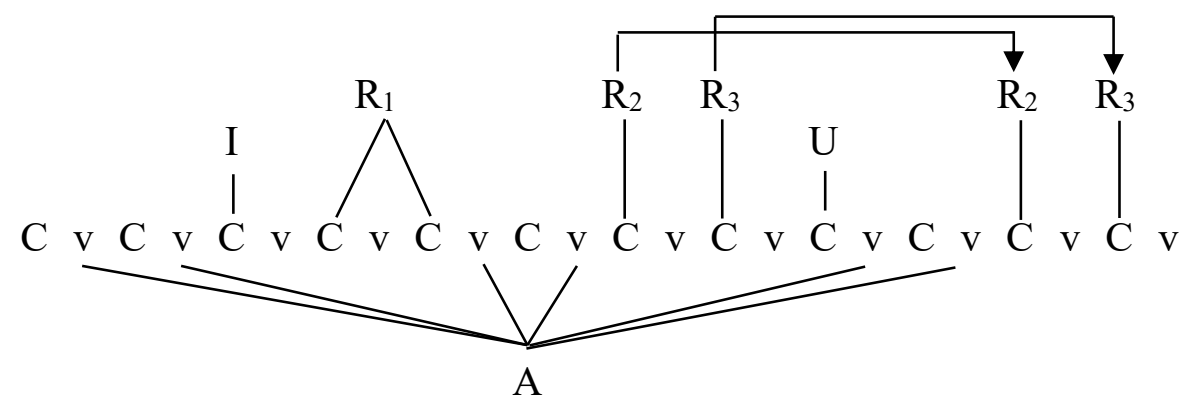

Two observations are in order. First, the template consists of a sequence of CV units, following the so-called CVCV model (Lowenstamm 1996). As an offspring of Government Phonology (Kaye et al. 1990), the CVCV approach to syllable structure holds that syllabic constituency in all languages boils down to strict alternations of non-branching onsets and non-branching nuclei, i.e. $\mathrm{C}$ and $\mathrm{V}$ positions, which interact laterally to derive different surface syllable types (Scheer 2004). The familiar closed syllables, long vowels and geminates are represented as follows:

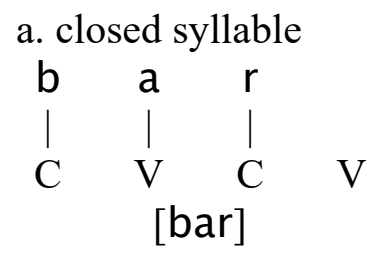

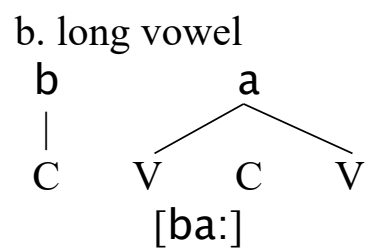<smiles>CCCCCCC</smiles>

Second, we take for granted in (3) that the three a's displayed in each Tagnawt form are connected to two positions (1a). Evidence for this will come at the end of the analysis.

\footnotetext{
${ }^{4}$ Actually, Tagnawt consists of a general process of reduplication. This is true for the segmental material (all root-C's are either geminated or reduplicated) as well as for the structure of the template itself. The template in (3) is to be construed as resulting from the reduplication of a more basic template of the form $\mathrm{CV}$ (CV) CV CV, the same one originally proposed by Guerssel and Lowenstamm (1990) in the case of Classical Arabic (on a similar process of reduplication in another secret language deriving from Tashlhiyt Berber, used by women, namely Taqjimit, see Lahrouchi and Ségéral 2009). The question as to the internal structure attributed to the template in (3) is not relevant to this paper and will therefore not be further addressed.
} 
Since we have so far considered only triconsonantal forms, one could argue that the shape of the template in (3), and particularly the number of CV units it contains, is motivated only by the space necessary for the accommodation of the segmental material obtained in triconsonantal forms. In fact, all formations in Tagnawt crucially require this template, for the reason that they all are triconsonantal formations ${ }^{5}$. Indeed, in the case Tagnawt inherits fewer than three consonants from the input, epenthetic processes provide the missing material.

Biconsonantal forms use an epenthetic $t$ or I to compensate for the missing radical while monoconsonantal forms use both. The examples in (5) illustrate the situation in the biconsonantal formations:

\begin{tabular}{|c|c|c|c|}
\hline \multirow[b]{2}{*}{ a. } & Tashlhiyt & Tagnawt & \\
\hline & $a m z^{\varsigma}$ & ajttamz $z^{\Upsilon} w a m z^{\varsigma}$ & take \\
\hline \multirow{7}{*}{ b. } & anf & ajttanfwanf & avoid \\
\hline & $\operatorname{ad}^{\top} n$ & $\operatorname{ajttad}^{\uparrow} n w a d^{\uparrow} n$ & be sick \\
\hline & $\mathrm{ak}^{\mathrm{w} r}$ & ajttak $^{w} r^{2}$ ak $^{w} r$ & steal \\
\hline & $\mathrm{i}-\mathrm{fl}$ & ajffalwalli & he let \\
\hline & sala & ajssalwalli & be involved \\
\hline & sllil & ajssalwalli & whiten, wash \\
\hline & kl & ajkkalwalli & spend the day \\
\hline
\end{tabular}

The examples in (5a) show forms where $t$ replaces the missing $R_{1}$ in Tashlhiyt. The examples in (5b) show forms where $\mathrm{R}_{3}$ is missing. The corresponding forms in Tagnawt all end in $\mathrm{i}$. We analyse this final $\mathrm{i}$ as the vocalized form of an epenthetic I playing the role of the

\footnotetext{
${ }^{5}$ Except for some quadriconsonantal formations dealt with at the end of the paper. Though displaying four radical consonants, they do not require a different template, as we will demonstrate.
} 
missing $\mathrm{R}_{3} .{ }^{6}$ This is ascertained by the case of triconsonantal words in Tashlhiyt where I is the third radical (this element surfaces as [i] or [j] depending on whether a consonant or a vowel precedes). Indeed, in Tagnawt such words end in $\mathrm{i}$ as well. Examples are in (6):

$\begin{array}{lll}\text { Tashlhiyt } & \text { Tagnawt } & \\ \mathrm{imz} z^{\Upsilon} \mathrm{ij} & \text { ajmmaz'wazz'i } & \text { be small } \\ \mathrm{iz}^{\Upsilon} \text { duj } & \text { ajzz'adwaddi } & \text { be heavy } \\ \mathrm{nfi} & \text { ajnnafwaffi } & \text { shelter } \\ \mathrm{d}^{\Upsilon} \mathrm{ni} & \text { ajdd'anwanni } & \text { be fat } \\ \text { zri } & \text { ajzzarwarri } & \text { cross }\end{array}$

Yet the third radical I never surfaces in the position normally identified in (3) by the first instance of $\mathrm{R}_{3}$, neither in triconsonantal forms in (6) where it is lexical, nor in biconsonantals in (5b) where it is epenthetic: nfi (6) leads to ajnnafwaffi and not to *ajnnafiwafi, and $\mathrm{fl}(5 \mathrm{~b})$ leads to ajffalwalli and not to *ajffaliwali7. However, in both cases the copy of $R_{2}$ is geminated: ajnnafwa $f f$, ajffalwa//. The number of $C$ positions in Tagnawt thus remains constant despite the difference in the location of the segmental material that the presence of $I$ in $R_{3}$ induces. The systematic gemination of the copy of $R_{2}$ in this case (and only in this case) is to be analysed as a compensation for the non-appearance of I in the

\footnotetext{
${ }^{6}$ Actually, I vocalizes in the final position when preceded by a consonant; it surfaces as $\mathbf{j}$ when preceded by a vowel. Many forms in Tashlhiyt Berber obey this constraint: e.g. zri (aorist) / zraj (imperfective) pass, kmi smoke / akmmaj smoker, $\mathrm{d}^{\top}$ ni be thick / ud'naj thick, fat. Guerssel (1986) shows that in Tamazight Berber any underlying $\mathrm{j}$ obligatorily surfaces as [i] word-finally (e.g. tusi she carried / tusjax she carried us). Standard analyses in phonological theory claim that glides and high vowels are distinguished in the position they occupy in the syllable: vowels appear in the nucleus position and glides surface in the onset or coda position (Kaye and Lowenstamm 1984, Selkirk 1984, and Levin 1985).

${ }^{7}$ The reason why $\mathrm{j}$ does not appear in $\mathrm{R}_{3}$ remains opaque to us. This may result from specific phonological constraints at work in Tashlhiyt Berber.
} 
first instance of $\mathrm{R}_{3}$ in Tagnawt. Compare, in this respect, the shape of a triconsonantal word (7a) with that of a word containing $I$, inherited or epenthetic, in $\mathrm{R}_{3}(7 \mathrm{~b})$ :

(7)

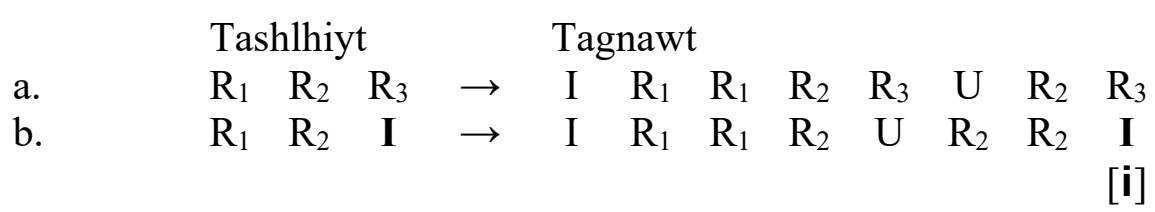

The representation in (8) illustrates the facts:

(8) nfi $\rightarrow$ ajnnafwaffi

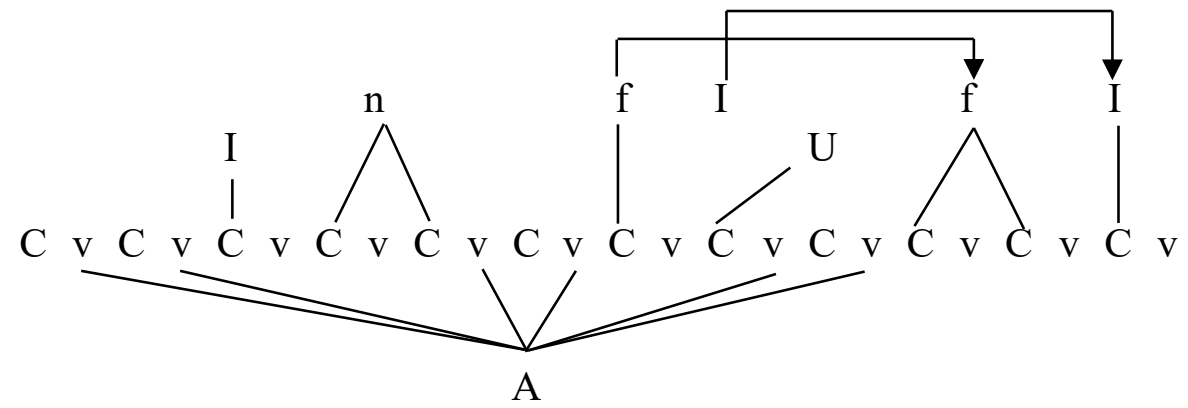

Monoconsonantal formations further establish the process of epenthesis just described.

In the examples in (9), the only radical inherited from Tashlhiyt is construed as $\mathrm{R}_{1}$ in Tagnawt, while the missing $\mathrm{R}_{2}$ and $\mathrm{R}_{3}$ are replaced by $\mathrm{t}-$ and I respectively.

(9)

\begin{tabular}{|c|c|c|}
\hline Tashlhiyt & Tagnawt & \\
\hline i-ga & ajggatwatti & he is \\
\hline$i-z z^{\Upsilon} a$ & ajzz’atwatti & he chases after \\
\hline kk & ajkkatwatti & pass by \\
\hline $\iint$ & 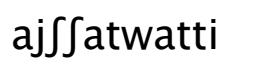 & eat \\
\hline$t-33 i-t$ & aj33atwatti & you recovered \\
\hline is & ajssatwatti & interrogative "do...?" \\
\hline
\end{tabular}


The operations are represented in (10):

(10) i-ga $\rightarrow$ ajggatwatti

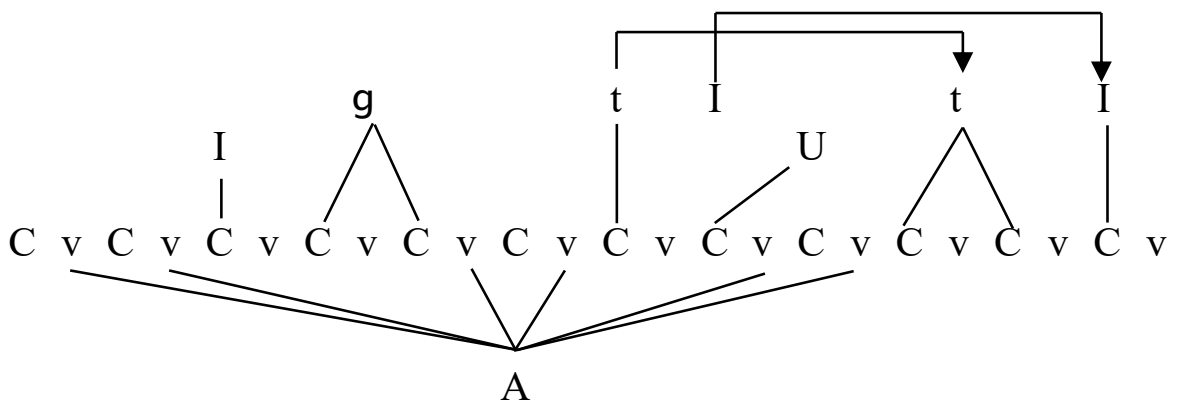

All Tagnawt forms corresponding to tri-, bi- and monoconsonantal words in Tashlhiyt are thus triconsonantal, from the input or by means of epenthesis. The situation is summarized in (11):

Radical material

\begin{tabular}{|c|c|c|c|c|c|c|c|}
\hline \multicolumn{4}{|c|}{ a. Tashlhiyt } & & \multicolumn{3}{|c|}{ b. Tagnawt } \\
\hline $3 R$ & $\mathrm{R}_{1}$ & $\mathrm{R}_{2}$ & $\mathrm{R}_{3}$ & $\rightarrow$ & $\mathrm{R}_{1}$ & $\mathrm{R}_{2}$ & $\mathrm{R}_{3}$ \\
\hline \multirow{2}{*}{$2 R$} & $\mathrm{R}_{1}$ & $\mathrm{R}_{2}$ & & $\rightarrow$ & $\mathrm{R}_{1}$ & $\mathrm{R}_{2}$ & I \\
\hline & & $\mathrm{R}_{2}$ & $\mathrm{R}_{3}$ & $\rightarrow$ & $\mathbf{t}$ & $\mathrm{R}_{2}$ & $\mathrm{R}_{3}$ \\
\hline $1 R$ & $\mathrm{R}_{1}$ & & & $\rightarrow$ & $\mathrm{R}_{1}$ & t & I \\
\hline
\end{tabular}

The treatment of Tashlhiyt quadriconsonantal words in Tagnawt provides further evidence. Indeed, most Tashlhiyt quadriconsonantal words lose one radical (always a sonorant) in Tagnawt, either $\mathrm{R}_{2}(12 \mathrm{a}), \mathrm{R}_{4}(12 \mathrm{~b})$, or (less frequently) $\mathrm{R}_{3}(12 \mathrm{c})$ :

$$
\text { Tashlhiyt Tagnawt }
$$

a. $\mathrm{R}_{1} \mathrm{R}_{2} \mathrm{R}_{3} \mathrm{R}_{4} \rightarrow \mathrm{R}_{1} \mathrm{R}_{2} \mathrm{R}_{3} \mathrm{R}_{4}$ asrdun ajssadnwadn mule

$\begin{array}{llll} & \text { aglzim } & \text { ajggazmwazm } & \text { pickaxe } \\ & \text { asngar } & \text { ajssagrwagr } & \text { maize, corn } \\ \text { b. } \mathrm{R}_{1} \mathrm{R}_{2} \mathrm{R}_{3} \mathrm{R}_{4} \rightarrow \mathrm{R}_{1} \mathrm{R}_{2} \mathrm{R}_{3} \mathrm{R}_{4} & \mathrm{~g} \mathrm{dr} & \text { ajggazdwazd } & \text { moan }\end{array}$



tagrtilt
ajggartwart
plait
amaz'duj
ajmmaz'dwaz'd
heavy
c. $\mathrm{R}_{1} \mathrm{R}_{2} \mathrm{R}_{3} \mathrm{R}_{4} \rightarrow \mathrm{R}_{1} \mathrm{R}_{2} \mathrm{R}_{3} \mathrm{R}_{4}$
agzajlu
ajggazlwazl
small

These forms lose one radical in Tagnawt for the same reason that mono- and biconsonantal forms resort to epenthesis, and triconsonantal forms displaying $\mathrm{I}$ in $\mathrm{R}_{3}$ (inherited or epenthetic) reduplicate and geminate $\mathrm{R}_{2}$ : they all use a unique template, the one in (3).

The "rule of the game" in Tagnawt can therefore be stated as in (13):
(13) a. one unique template (3) underlies all formations in Tagnawt
b. the template must be filled

Let us now turn to the question of vowels.

\section{Vowels}

The analysis of word-formation in Tagnawt provides two different arguments in favour of our assumptions in (1) about the representation of peripheral vowels in Tashlhiyt, repeated for convenience in (14):
a. $\quad \mathrm{V}, \mathrm{V}$
A, I, U
$\rightarrow \quad[\mathrm{a}],[\mathrm{i}],[\mathrm{u}]$

b. V
A, I, U
$\rightarrow \quad[\partial] / \varnothing$ 
The first argument is drawn from the final $i$ which arises whenever the last radical is $I$. Phonetically, this vowel is short: [i]. Phonologically, however, it must be associated to two positions (15b), as stated in (14a):

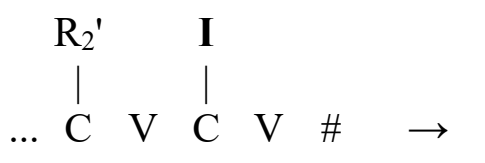

a.

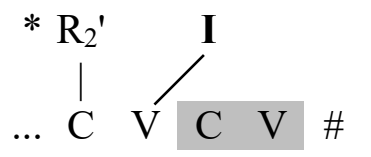

b.

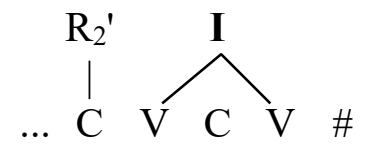

Indeed, if I were associated to only one V position as in (15a), the template would not be filled entirely, the final CV (shadowed) remaining empty. This is hardly tenable in light of the facts discussed previously. In particular, it would be difficult to explain why Tagnawt resorts to various processes (epenthesis, reduplication and gemination of the same segment, or conversely deletion of one root consonant) in order to fit the template, while I connects here to only one $\mathrm{V}$ position, leaving the final $\mathrm{CV}$ unidentified.

The second argument is provided by the behaviour of certain quadriconsonantal words that we have let aside so far. Indeed, not all Tashlhiyt quadriconsonantal words lose one root consonant in Tagnawt. Consider the examples in (16):

\begin{tabular}{|c|c|c|}
\hline Tashlhiyt & Tagnawt & \\
\hline xurbs & ajxxərbswabs & scratch \\
\hline zz'Imd & ajzz`əlmdwamd & be clumsy \\
\hline Ilustm & ajlləStmwatm & crawl \\
\hline ggrml & ajggərmlwaml & be crusty \\
\hline agnfur & ajggənfrwafr & face \\
\hline $\operatorname{aqr} \int a l$ & ajqqərflwasl & card \\
\hline
\end{tabular}


These words keep the original material in Tagnawt. The four radicals in Tashlhiyt forms all appear in the corresponding forms in Tagnawt. However,

i. one of these radicals, namely $\mathrm{R}_{2}$, is not repeated. It appears only once in the form;

ii. the melody obtained in these words, and only in these words, contains $ə$ after the geminated $R_{1}$. All other words in Tagnawt are vocalized invariably in a.

If in Tagnawt peripheral vowels were connected to only one V position, we would get an undesirable outcome where:

i. two different templates are required, one for all formations discussed previously and the other for the formations in (16). Furthermore, within such an analysis there is no way to explain why Tagnawt does not use as many templates as there are forms: if there are two templates, why not three or four? What are all the operations discussed so far (epenthesis, gemination of the copy of $\mathrm{R}_{2}$, deletion of one radical consonant) good for?

ii. the systematic appearance of $ə$ instead of a whenever and only when four radical consonants are kept, has no possible logical explanation.

Conversely, if peripheral vowels in Tashlhiyt are analysed as proposed in (14a), that is associated to two positions, then there is no need to state two different templates: the conservation of all four radicals is a possibility the template (3) offers. If this possibility is exploited, it simply entails that only one V position is available. This is shown in (17): 


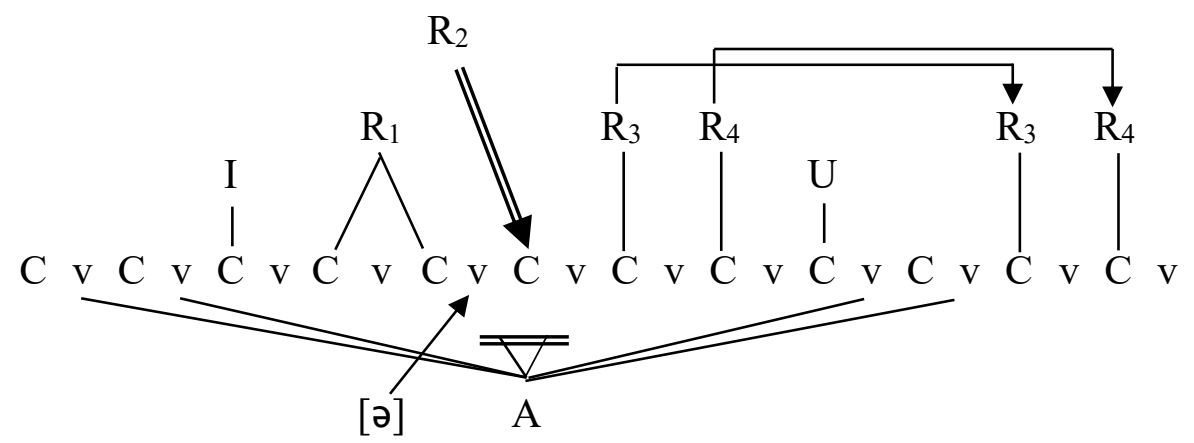

As a consequence of the association of $\mathrm{R}_{2}$ to the template, the vowel $\mathrm{A}$ has no longer access to two V positions. Crucially, at this very moment, A no longer surfaces in [a]. Instead, $[ə]$ appears.

If A required only one V-position for it to be realized in the surface form, then all quadriconsonantal forms would maintain their medial [a] as in other forms. In other words, Tagnawt quadriconsonantal formations in (16) cannot be accounted for unless both assumptions made in (1) about the phonological representation of peripheral and central vowels are correct.

Finally, regarding [i], there is no evidence in the data that this vowel alternates with $[ə]$ under the same conditions as [a], for the reason that Tagnawt forms are all invariably vocalized in A. However, we have shown that the templatic constraints imply that [i], resulting from the vocalization of a palatal glide, must be "long", exactly like [a]. As for [u], though no example of it is available in Tagnawt, there is no reason to think that it is different from the other two vowels.

\section{References}

Bendjaballah, Sabrina. 2001. The negative preterite in Kabyle Berber. Folia Linguistica 34: $185-223$.

Bendjaballah, Sabrina. 2005. Longueur phonologique des voyelles en kabyle. Etudes et documents berbères 22: 47-69. 
Coleman, John. 1996. Declarative syllabification in Tashlhit Berber. In Current Trends in Phonology: Models and Methods, Vol. 1, ed. Jacques Durand and Bernard Laks, 177218. Salford: European Studies Research Institute, University of Salford.

Coleman, John. 1999. The nature of vocoids associated with syllabic consonants in Tashlhiyt Berber. In Proceedings of the XIVth International Congress of Phonetic Sciences, vol. 1, ed. John Ohala, Yoko Hasegawa, Manjari Ohala, Daniel Granville, and Ashlee C. Bailey, 735-8. Berkeley: University of California.

Coleman, John. 2001. The phonetics and phonology of Tashlhiyt Berber syllabic consonants. Transactions of the Philological Society 99: 29-64.

Dell, François, and Mohamed Elmedlaoui. 2002. Syllables in Tashlhiyt Berber and in Moroccan Arabic. Dordrecht: Kluwer Academic Publishers.

Douchaïna, Rqia. 1996. Tagnawt, un parler secret des femmes berbères de Tiznit (sud-ouest marocain). PhD diss., Paris: INALCO.

Douchaïna, Rqia. 1998. La morphologie du verbe en tagnawt. Etudes et documents berbères 15/16: 197-210.

Guerssel, Mohamed. 1986. Glides in Berber and syllabicity. Linguistic Analysis 17: 1-12.

Guerssel, Mohamed, and Jean Lowenstamm. 1990. Classical Arabic apophony. Ms UQAM and University Paris 7.

Idrissi, Ali. 2000. On Berber plurals. In Research in Afroasiatic Grammar, ed. Jacqueline Lecarme, Jean Lowenstamm, and Ur Shlonsky, 101-24. Amsterdam: John Benjamins. Kaye, Jonathan, Jean Lowenstamm. 1984. De la syllabicité. In Forme Sonore du Langage, ed. François Dell, Daniel Hirst, and Jean-Roger Vergnaud, 123-59. Paris: Hermann. Kaye, Jonathan, Jean Lowenstamm, and Jean-Roger Vergnaud. 1990. Constituent structure and government in phonology. Phonology 7: 193-231. 
Lahrouchi, Mohamed, and Philippe Ségéral. 2009. Morphologie gabaritique et apophonie dans un langage secret féminin (Taqjmit) en berbère tachelhit. Revue canadienne de Linguistique / Canadian Journal of Linguistics 54: 291-316.

Levin, Juliette. 1985. A Metrical theory of syllabicity. PhD diss., MIT.

Lowenstamm, Jean. 1991. Vocalic length and centralization in two branches of Semitic. In Semitic Studies in Honor of Wolf Leslau on the Occasion of his 85th Birthday, vol. 2, ed. Alan S. Kaye, 949-65. Wiesbaden: Harrasowitz.

Lowenstamm, Jean. 1996. CV as the only syllable type. In Current Trends in Phonology: Models and Methods, vol. 2, ed. Jacques Durand, and Bernard Laks, 419-41. Salford: European Studies Research Institute, University of Salford.

Scheer, Tobias. 2004. A lateral theory of phonology: what is CVCV and why should it be?. Berlin - New York: Mouton de Gruyter.

Selkirk, Elisabeth. 1984. On the major class features and syllable theory. In Language Sound Structures, ed. Mark Aronoff, Richard Oehrle, Frances Kelley, and Bonnie Wilker Stephens, 107-36. Cambridge, MA: MIT Press. 